\title{
HUBUNGAN KEPEMIMPINAN KEPALA SEKOLAH DAN PELAYANAN DENGAN KEPUASAN SISWA
}

\author{
Yusuf \\ Sekolah Tinggi Ilmu Tarbiyah (STIT) Muhammadiyah Berau Kaltim \\ J1. Jendral Sudirman Tanjung Redeb Berau Kaltim \\ Email:yusufjr1953@gmail.com
}

\begin{abstract}
This research aimed to find out (1) relationship between headmaster's leadership with student's satisfaction, (2) relationship betweenservice with student's satisfaction, (3) relationship between headmaster's leadership and service collectively with student's satisfaction. Research method used in this research is quantitativemethod with correlation survey technique. The sampling technique used is multi stage random sampling. The responden in this research is Senior High School's students in BerauRegency with population was 3486students and sample was171students. The resultof this research shows: First, there was a significant relationship between headmaster leadership with student's satisfaction. Second, there was a significant relationship between service withstudent'ssatisfaction.Third, there was asignificant relationship between headmaster leadership and servicecollectively with student's satisfaction.
\end{abstract}

Keywords: headmaster's leadership, service, student's satisfaction.

\begin{abstract}
Abstrak: Penelitian ini bertujuan untuk mengetahui (1) hubungan antara kepemimpinan kepala sekolah dengan kepuasan siswa (2) hubungan antara pelayanan dengan kepuasan siswa, (3) hubungan antara kepemimpinan kepala sekolah dan pelayanan secara bersamasama dengan kepuasan siswa. Metodepenelitian yang digunakan dalam penelitian iniadalah metode kuantitatif dengan teknik survey korelasional. Teknik sampling yang digunakan adalah teknik multi stage random sampling. Responden dalam penelitian ini adalah Siswasiswi SMA Negeri yang berada di Kabupaten Berau dengan populasi sebanyak 3486 siswa dan sampel sebanyak 171 siswa. Hasil penelitian ini menunjukkan bahwa: Pertama, terdapat hubungan yang signifikan antara kepemimpinan kepala sekolahdengan kepuasan siswa. Kedua, terdapat hubungan yang signifikan antara pelayanan dengan kepuasan siswa. Ketiga, terdapat hubungan yang signifikan antara kepemimpinan kepala sekolah dan pelayanan secara bersama-sama dengan kepuasan siswa.
\end{abstract}

Kata Kunci: Kepemimpinan kepala sekolah, pelayanan, kepuasan.

Bagi bangsa yang maju,pendidikan merupakan sebuah kebutuha, seperti halnya dengan kebutuhan papan, sandang, dan pangan.Bahkan dalam institusi terkecil seperti keluarga, pendidikan merupakan kebutuhan utama. Pendidikan adalah kebutuhan dan kewajiban. Dalam Islam, pendidikan didasarioleh kesadaran bahwa setiap muslim wajib menuntut ilmu. Di dalam Hadist menyebutkan, "me-nuntut ilmu wajib bagi setiap muslim" (HR. Ibnu Majah).

Namun, miris rasanya menatap kondisi pendidikan kita,mutunya rendah. Padatahun
2013 Human development Index kita berada pada peringkat 121 dari 185 negaradan kita negara berada diperingkat ke64 untuk pendidikan di seluruh dunia dari 120 negara (Yusuf, 2014:7). Namun, lebih menyayangkan lagi menurut Programme for International Study Assessment (PISA) 2012 menempatkan Indonesia sebagai salah satu negara dengan peringkat terendah dalam pencapaian mutu pendidikan, pemeringkatan tersebut dilihat dari skor yang dicapai pelajar usia 15 tahun dalam kemampuan membaca, matematika, dan sains (Tempo, 2013). 
Belum lagi, adanya dikotomi antara pendidikan agama dengan pendidikan umum. Hal ini tampak jelas pada UU Sisdiknas No. 20 tahun $2003 \mathrm{Bab}$ VI tentang jalur, jenjang dan jenis pendidikan bagian kesatu (umum) pasal 15 yang berbunyi: jenis pendidikan mencakup pendidikan umum, kejuruan, akademik, profesi, vokasi, keagamaan dan khusus (Depdiknas, 2008:9). Sistempendidikan yang dikotomi seperti ini gagal melahirkan manusia sholeh.

Semakin berkembangnya sains dan teknologi di era globalisasi, dunia pendidikan mengalami perubahan dan dihadapkan pada masalah yang harus diselesaikan, termasukmasalah mutu pendidikan seperti mutu pengajaran, kualifikasi kepala sekolah dan guru, pelayanan (di sekolah), mutu input, output serta outcome lulusan. Triwiyanto (2017:13) menyatakan bahwa permasalahan yang dihadapi dunia pendidikan Indonesia adalah pemerataan, mutu, relevansi, efektivitas manajemen, dan manajemen pendidikan yang semuanya terkendala pada penggunaan biaya pendidikan.

Dalam hal layanan, pendidikandihadapkan pada masalah mutu,hal ini dapat berpengaruh bagikepuasan siswa. Dalam konsep Total Quality Service (mutu pelayanan total), Perlu melibatkanmanager (kepala sekolah) dan karyawan (guru dan tata usaha) untuk memperbaiki secara berkesinambungan proses-proses pendidikan, agardapat memenuhi harapan-harapan para pelanggan pendidikan (Tjiptono, 2008:2).Kepala sekolah berpengaruh sangat besar dalam berlangsungnya pendidikan, pembelajaran serta mutu layanan di sekolah yang pada tahap selanjutnya dapat dirasakan oleh para siswa pada tingkat kepuasan tertentu.

\section{METODE}

Penelitian ini dilaksanakan pada Sekolah Menengah Atas (SMA) Negeri yang terletak di Kabupaten Berau. Penelitian ini menggunakan metode penelitian kuantitatif. Penelitian ini digunakan untuk meneliti pada populasi atau sampel tertentu, teknik pengambilan sampel pada umumnya dilakukan secara random, pengumpulan data menggunakan instrumen penelitian, analisis data bersifat kuantitatifdengan tujuan untuk menguji hipotesis yang telah ditetapkan (Sugiyono, 2008:14). Dalam pengumpulan data menggunakan metode survey dengan teknik korelasional. Survey adalah penelitian yang berupaya mengumpulkan data dari sam-pel populasi untuk menentukan status populasi dalam hubungannya pada varia-bel yang diteliti (Tim Penyusun Pedoman Tesis dan Disertasi Pascasarjana UHAMKA, 2008:6).

Dalam pengumpulan data, peneliti mengedarkan kuesioner kepada sampel yang ditetapkan. Arikunto (2013:174) suatu penelitian dinamakan penelitian sampel apabila bermaksud untuk menggeneralisasi hasil penelitian sampel.

Dalam penelitian ini terdapat dua variabel bebas, yaitu kepemimpinan ke-pala sekolah (X1) dan pelayanan (X2) serta satu variabel terikat yaitu kepuasan siswa (Y). Selanjutnya variabel peneli-tian di hubungkan antara satu dengan yang lain. Adapun pola hubungan ini adalah: (1) hubungan antara variabel kepala sekolah (X1) dengan kepuasan siswa(Y), (2) hubungan antara variabel pela-yanan (X2) dengan kepuasan siswa (Y) dan (3) hubungan antara variabel kepala sekolah (X1) dan pelayanan (X2) secara bersamasama dengan variabel kepuasan siswa (Y). Ketiga pola hubunganini di-gambarkan pada Gambar 1.

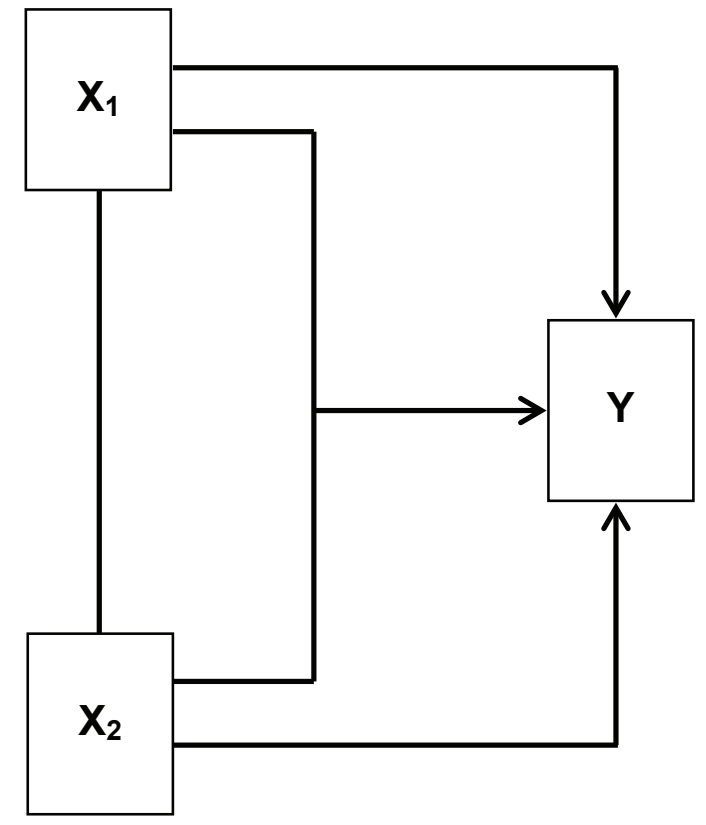

Gambar 1.Bagan Hubungan Antar Variabel Penelitian

\section{Keterangan:}

X1 : Variabel Kepemimpinan Kepala Sekolah

X2 : Variabel Pelayanan

Y : Variabel Kepuasan Siswa 
Populasi pada penelitian 3486 siswa yang tersebar di 14 Sekolah Menengah Atas (SMA) Negeri yang berada di Kabupaten Berau. Adapun sampelnya, menggunakan jenis sampel multi stage random sampling. Peneliti memilih secara random 4 dari 14 sekolah yang mewakili 4 kecamatan terdekat dan memiliki jumlah pelajar (siswa-siswi) terbesar. Kemudian dengan pertimbangan tertentu peneliti hanya mengambil sampel siswa secara acak dikelas XI dan XII. Kelas XI dan XII dijadikan sebagai sampel penelitian karena pada masa itu siswa telah banyak berinteraksi dengan kepala sekolah dan banyak merasakan pelayanan di sekolah.

Adapun rumus yang digunakan untuk memperoleh sampel adalah dengan rumus slovin sebagai berikut.

$$
\begin{aligned}
& n=\frac{N}{1+N \mathrm{e}^{2}} \\
& \mathrm{n}=\text { Sampel } \\
& \mathrm{N}=\text { Populasi } \\
& \mathrm{e}=\text { Margin kesalahan }(0,1)
\end{aligned}
$$

Kemudian, diperoleh sampel sebanyak 87 siswa dari kelas XI dan 84 siswa dari kelas XII, total keseluruhan 171 siswa.

Analisis statistik dalam penelitian ini meliputi: Pertama, Uji Persyaratan Analisis. Agar pengambilan keputusan pada pengambilan hipotesis dapat diper-caya maka harusmemenuhi asumsi-asumsi dengan menggunakan: Uji normalitas, linearitas,homogenitas dan asumsi multikolinearritas. Selanjutnya asumsi-asumsi tersebut diuji dengan program SPSS versi 21.0.Kedua, teknik pengujian hipotesisdengan uji regresi linier.Untuk keperluan pengujian ketiga hipotesis penelitian digunakan teknik sebagai berikut: (1) Teknik regresi linier sederhana, digunakan untuk mencari dan menguji persamaan regresi yang dimaksud, yaitu persamaan regresi $\mathrm{Y}$ atas $\mathrm{X} 1$, persamaan regresi kepuasan $\mathrm{Y}$ atas $\mathrm{X} 2$ dan dilanjutkan dengan korelasi sederhana; (2) Teknik regresi linier ganda, digunakan untuk menguji ketiga hipotesis apakah terdapatkorelasi yang berarti apabila kedua variabel bebas secara bersama-sama (X1 dan X2) dikorelasikan dengan variabel terikat (Y) dengan terlebih dahulu menguji persamaan reg-resi linier ganda; dan (3) Teknik korelasi parsial, adapun tujuannya untuk menge-tahui besarnya koefisien determinasidari masing-masing variabel bebas yang disumbangkan terhadap variabel terikat.

Adapun hipotesisstatistik dalam pe-nelitian ini: (1) Tidak terdapat hubungan signifikan antara kepemimpinan kepala sekolah dengan kepuasan siswa (Ho) dan Terdapat hubungan signifikan antara kepemimpinankepala sekolah dengan kepuasan siswa (H1). (2) Tidak terdapat hubungan signifikan antara pelayanan dengan kepuasan siswa (Ho) dan Terdapat hubungan signifikan antara pelayanan dengan kepuasan siswa (H1). (3) Tidak terdapat hubungan signifikan antara kepemimpinankepala sekolah dan pelayanan dengan kepuasan siswa (Ho) dan Terdapat hubungan signifikan antara kepemimpinan kepala sekolah dan pela-yanansecara bersamasama dengan kepuasan siswa (H1).

\section{HASIL}

Melalui datayang dijaring melalui penyebaran angket, dengan jumlah pernyataan sebanyak empat puluh butir instrumen dengan penggunaan skala pilihan jawaban skala 5, maka didapatkan.

\section{Variabel Kepemimpinan Kepala Sekolah}

Skorteoretik antara 40-200,sedangkan skor empirik menyebar dari skor terendah 137 sampai dengan skor tertinggi 197, dengan skor total yaitu 29010, rata-rata (M) 169,649, simpangan baku (SD) 10,823, modus (Mo) 175, median (Me) 171 , dan varians 117,135.

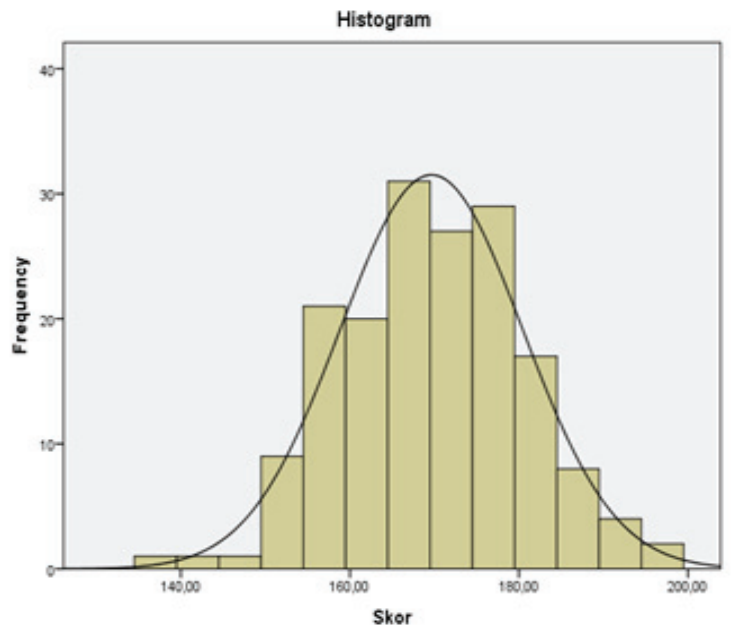

Gambar 2. Histogram Skor Variabel X1 


\section{Variabel Pelayanan Sekolah}

Skorteoretik antara 40 sampai dengan 200. Sedangkan skor empirik menyebar dari skor terendah 115 sampai skor tertinggi 185 dengan skor total yaitu 26129, rata-rata (M) 152,801 , simpangan baku (SD) 13,558, modus (Mo) 149, median (Me) 154 dan varians 183,831.

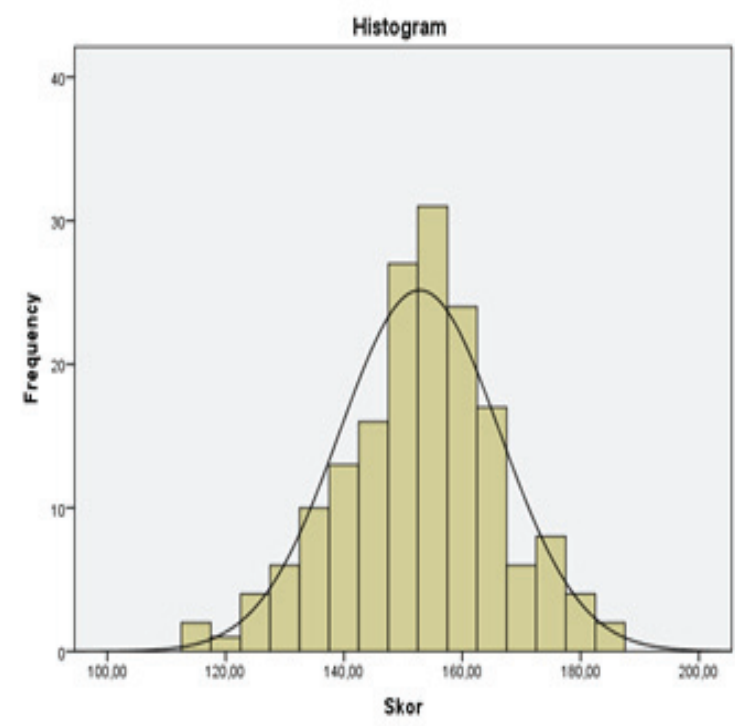

Gambar 3. Histogram Skor Variabel X2

\section{Variabel Kepuasan Siswa}

Skorteoretik antara 40 sampai 200. Sedangkan skor empirik menyebar dari skor terendah 104 sampai dengan skor tertinggi 184,dengan skor total yaitu 26191, rata rata (M) 153,164, simpangan baku (SD) 12,851, modus (Mo) 158, median (Me) 155 dan varians 165,150.

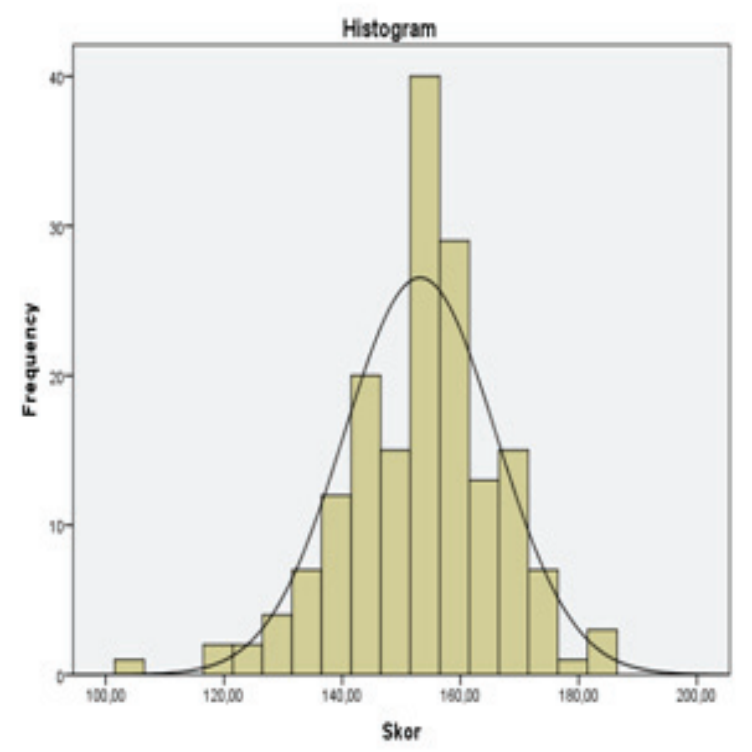

Gambar 4. Histogram Skor Variabel Y

\section{Uji Normalitas}

Sebelum melakukan uji hipotesis, dilakukan uji normalitas data yaitu untuk dapat mengetahui apakah sampel berasal dari data yang berdistribusi normal. Maka perlu diadakan uji sampel Kolmogrov Smirnov yaitu apabila Asymp. Sig $>$ taraf signifikan $(\alpha=0.05)$, maka dihasilkan sampel variabel berdistribusi normal.

Kesimpulannya bahwa:(1)Variabel Kepemimpinan Kepala Sekolah (X1) berdistribusi normal karena nilai Asmpy.Sig $>\alpha(0.05)$ yaitu: $0,732>0.05$.(2) Variabel Pelaya-nan (X2) berdistribusi normal karena didapat nilai Asmpy.Sig $>$ taraf signifikan $(\alpha=0,05)$ yaitu: $0,537>0,05$. (3) Varia-bel Kepuasan Siswa (Y) berdistribusi normal karena didapat nilai Asmpy.Sig $>$ taraf signifikan $(\alpha=0,05)$ yaitu: $0,088>0,05$.

\section{Uji Linearitas}

Uji linearitas bertujuan untuk me-ngetahui apakah dua variabel mempu-nyai hubungan yang linier atau tidak secara signifikan. Setelah data dianalisis dengan mengunakan Program SPSS ver-si 21. Dari tabel 4dan 5 diperoleh nilai signifikansi linieritynya adalah 0,00 . Karena signifikasinya kurang dari 0,05 ma-ka dapat disimpulkan bahwa, (1) antara variabel kepuasan siswa (Y) dan kepe-mimpinan kepala sekolah(X1) terdapat hubungan yang linier.(2) antara variabel kepuasan siswa dan pelayanan terdapat hubungan yang linier.

\section{Uji Homogenitas}

Uji homogenitas dimaksudkan untuk memperlihatkan bahwa dua atau lebih kelompok data sampel berasal dari popu-lasi yang memiliki variansi yang sama. Dari tabel 6, terlihat bahwa nilai sig $>0,05=0,200>0,05$. Berarti model reg-resi ganda adalah konstan atau variansi error adalah homogen.

\section{Uji Asumsi Multikolinearritas}

Multikolinierritas adalah terjadinya hubungan linier antara variabel bebas baik hubungan sempurna ataupun hubungan tidak sempurna. Model regresi yang baik seharusnya tidak terjadi korelasi diantara variabel bebas (tidak terjadi multikonieritas). Jika variabel bebas saling berkorelasi, maka variabel-variabel ini tidak ortogonal (variabel bebas yang nilai korelasi antar sesama variabel bebas sama dengan nol). Dampak dari multikolinearritas dalam model regresi ganda adalah mempunyai variansi atau kovariansi yang besar sehingga sulit 
mendapatkan taksiran yang tepat, menyebabkan interval estimasi cenderung lebih lebar dan nilai hitung statistik tidak signifikan memengaruhi variabel tidak bebas. Selanjutnya untuk mendeteksi adanya multikolinierritas dalam model regresi linier ganda digunakan nilai Variance Inflation Faktor(VIF) dan tolerance (TOL) dengan ketentuan tidak terjadi adanya multikolinearitas jika nilai tolerance (TOL)nya lebih besar 0,10 atau jika nilai Variance Inflation Faktor (VIF)nya lebih kecil 10,00.Dari tabel 7 terlihat bahwa tidak terjadi multikoli-nearritas.

\section{Pengujian Hipotesis}

\section{Hipotesis hubungan antara kepemimpinan} kepala sekolahdengan kepuasan siswa

Nilai yang tertera untuk uji regresi sederhana diperoleh Fhitung $=$ 49,011 dengan df pembilang adalah 1 dan df penyebut 169 , memiliki nilai yang lebih besar dari Ftabel $=3.90$ (untuk $\alpha=$ $5 \%$ ) dan Ftabel $=6.79$ (untuk $\alpha=1 \%$ ) serta sig $(0.00)$ lebih kecil dari $\alpha(0.05)$. Dengan demikian sesuai kaidah pengujian jika Fhitung $>$ Ftabel maka $\mathrm{H} 0$ ditolak dan jika sig $<\alpha$ maka $\mathrm{H} 0$ ditolak, dapat disimpulkan bahwa terdapat hubu-ngan yang signifikan antara kepemimpi-nan kepala sekolah (X1) dengan kepua-san siswa (Y). Nilai $\mathrm{R}$ square $=0,225=0.23=23 \%$. Variansi nilai kepuasan siswa dipengaruhi oleh kepe-mimpinan kepala sekolah (X1) sebesar 23\% sedangkan 77\% dipengaruhi oleh faktor lain.

\section{Hipotesis hubungan antara pelayanan dengan kepuasan siswa}

Dari nilai yang tertera pada tabel ANOVA untuk uji regresi sederha-na diperoleh Fhitung = 392,434 dengan df pem-bilang adalah 1 dan df penyebut 169 , memiliki nilai yang lebih besar dari Ftabel $=3.90$ (untuk $\alpha=5 \%$ ) dan Ftabel $=$ 6.79 (untuk $\alpha=1 \%$ ) serta sig (0.00) lebih kecil dari $\alpha(0.05)$. Dengan demikian sesuai kaidah pengujian jika Fhitung $>$ Ftabel maka H0 ditolak dan jika sig $<\alpha$ maka $\mathrm{H} 0$ ditolak, dapat disimpulkan bahwa terdapat hubungan signifikan antara pelayanan (X2) dengan kepuasan siswa (Y). Nilai R square $=0,699=69.9 \%$, dapat dijelaskan bah-wa variansi nilai kepuasan siswa dipengaruhi oleh pelayanan (X2) sebesar $69.9 \%$ sedangkan $30.1 \%$ dipengaruhi oleh faktor lain.
Hipotesis hubungan secara bersama-sama antara kepemimpinan kepala sekolahdan pelayanan dengan kepuasan siswa

Nilai yang tertera pada tabel ANOVA, untuk uji regresi diperoleh Fhitung $=196,970$ dengandf pembilang adalah 2 dan df penyebut 168 , memiliki nilai yang lebih besar dari Ftabel= 3.05 (untuk $\alpha=5 \%$ ) dan Ftabel $=6.79$ (untuk $\alpha$ $=1 \%)$ serta sig $(0.00)$ lebih kecil dari $\alpha(0.05)$. Dengan demikian sesuai kaidah pengujian jika Fhitung $>$ Ftabel maka $\mathrm{H0}$ ditolak dan jika sig $<\alpha$ maka H0 di-tolak, dapat disimpulkan bahwa terdapat hubungan yang signifikan antara kepemimpinan kepala sekolah (X1) dan pelayanan (X2) secara bersama-sama dengan kepuasan siswa (Y). Nilai R square (koefisien determinasi) $=0,70=70 \%$, dapat dijelaskan bahwa variansi nilai ke-puasan siswa dipengaruhi oleh kepemimpinan kepala sekolah (X1) dan pela-yanan (X2) secara bersama-sama sebesar 70\% (tujuh puluh persen) sedangkan 30\% (tiga puluh persen) sisanya dipengaruhi oleh faktor lain.

\section{PEMBAHASAN}

Temuan penelitian menunjukkan bahwa terdapat hubungan yang signifikan antara kepemimpinan kepala sekolah dengan kepuasan siswa, kontribusi ini dapat ditunjukkan dengan nilai determinasi $23 \%$. Hal ini berarti bahwa kepemimpinan kepala sekolah berpengaruh terhadap kepuasan siswa secara signifikan.Artinya diyakini kepemimpinan kepala sekolah meningkatkan kepuasan siswa. Triwiyanto (2016:67) menyatakan organisasi sekolah perlu dijalankan dengan baik karena tugas guru dan kepala sekolah tidak hanya mengajar dan mendidik saja, semua harus bertanggung jawab dan diikut sertakan dalam menjalankan roda kehidupan sekolah secara keseluruhan.

Hasil penelitian ini memberi rekomendasi bahwakepemimpinan kepala sekolah sangat penting bagi peningkatan kepuasan siswa, oleh karena itu kepala sekolah harus mampu mengembangkan ilmu pengetahuannya dan metode yang digunakan dalam memengaruhi, menga-rahkan, memotivasi, membimbing, mengawasi guru dan karyawan dalam melaksanakan tugas-tugasnya sesuai dengan fungsi dan peran masing-masing sesuai dengan visi dan misi sekolah yang telah ditetapkan agar 
kepuasan siswaterhadap proses pendidikan di sekolah dapat meningkat. Sejalan dengan penenmuan tersebut, Anggraeni, Kusmintardjo, dan Nurabadi (2016:10) menyatakan kepala sekolah dapat dikatakan berhasil apabila kepala sekolah memahami dan menyadari keberadaan sekolah sebagai lembaga yang kompleks, serta mampu melaksanakan peranan kepala sekolah sebagai seseorang yang bertanggung jawab untuk memimpin dan mengendalikan sekolah.

Pengujian hipotesis penelitian ini menunjukkan bahwa terdapat hubungan yang signifikan antara pelayanan dengan kepuasan siswadi SMA Negeri Kabupaten Berau. Kontribusi hubungan signifikan ini dapat ditunjukkan dengan nilai determinasi $69.9 \%$. Hal ini berarti bahwa pelayanan di sekolah berpengaruh terhadap kepuasan siswa secara signifikan. Artinya diyakini pelayanan yang baik di sekolah meningkatkan tingkat kepuasan siswa. Hasil penelitian ini memberikan rekomendasi bahwa kepala sekolah (headmaster), guru (teacher) dan karyawan penting untuk memberikan layanan yang prima terhadap pelanggan (dalam hal ini adalah siswa).Liana, Benty, dan Supriyanto (2016:39) menyatakan bahwa: (1) faktor yang mempengaruhi kepuasan yaitu: (a) faktor layanan sarana dan prasarana, (b)faktor layananpengelolaan,(c) faktor layanan pada aspek pembelajaran, (d) faktor layanan yang diberikan pendidik dan tenaga administrasi sekolah, dan (e) faktor layanan pada aspek kompetensilulusan;(2) tingkat kepuasan orang tua peserta didik terhadap layanan pendidikan ada pada kategori sangat tinggi; dan (3) faktor yang paling dominan mempengaruhi kepuasan terhadap layanan pendidikan adalah faktor layanan sarana dan prasarana.

Dalam hal ini yang perlu dilakukan adalah memahami kebutuhan dan keinginan pelanggan termasuk memahami tipe-tipe pelanggan, mengembangkan data kebutuhan dan keinginan setiap segmen pelanggan (siswa) serta pemanfaatan informasi yang diperoleh untukdisusun dalam suatu kerangka strategis. Kusumaningrum, Triwiyanto, dan Gunawan (2016:1) menyatakan lingkungan sekolah yang dinamis, menjadi pembelajaran yang mendalam untuk perencanaan ke depan lebih baik.

Koefisien determinasi hubungan variabel ini adalah sebesar 0.70 , artinya kepemimpinan kepala sekolah dan pelayanan memberikan kontribusi terhadap kepuasan siswa sebesar 70\%. Hasil pengujian hipotesis ini dapat dijelaskan bahwa kepemimpinan ke-pala sekolah dan pelayanan sangat penting bagi peningkatan kepuasan siswa. Karena pentingnya kepemimpinan kepala sekolah dan pelayanan, maka kepala sekolah, karyawan, guru dan pihak-pihak yang terkait harus bersama-sama mengupayakan agar kedua variabel pendukung kepuasan siswa ini dapat meningkat dan berperan secara maksimal.

\section{KESIMPULAN DAN SARAN}

\section{Kesimpulan}

Berdasarkan hasil pengujian hipotesis, kesimpulan penelitian dapat dirumuskan sebagai berikut: (1) Terdapat hubungan yang signifikan antara kepemimpinan kepala sekolah dengan kepuasansiswa. Hal ini memberikan pengertian bahwa semakin positif atau semakin baik kepemimpinan kepala sekolah, diiringi dengan meningkatnya kepuasan siswa. Demikian pula sebaliknya, apabila kualitas kepemimpinan kepala sekolah buruk, diiringi dengan menurunnya kepuasan siswa. (2) Terdapat hubungan yang signifikan antara pelayanan dengan kepuasan siswa. Hal ini memberikan pengertian bahwa semakin positif atau semakin baik pelayanan di sekolah, diiringi dengan meningkatnya kepuasan siswa. Demikian pula sebaliknya, apabila kualitas pelayanan di sekolah buruk, diiringi dengan menurunnya kepuasan siswa. (3) Terdapat hubungan yang signifikan antara kepemimpinan kepala sekolah dan pelayanan secara bersamasama dengan kepuasan siswa. Hal ini berarti semakin baik kepemimpinan kepala sekolah dan pelayanan, diiringi dengan meningkatnya tingkat kepuasan siswa. Sebaliknya, apabila kualitas kepemimpinan kepala sekolah dan pelayanan di sekolah buruk, maka tingkat kepuasan siswa menurun.

\section{Saran}

Berdasarkan hasil penelitian dan kesimpulan, dapat dikemukakan saran-saran antara lain sebagai berikut: (1) Kepala sekolah hendaknya dapat mening-katkan kepemimpinan yang efektif guna meningkatkan kepuasan siswa dalam mengenyam pendidikan di sekolah 
serta menciptakan strategi layanan pendidikan yang memadai, unggul dan prima; (2) Kepada pihak-pihak terkait yang berkompeten, dalam hal iniKementerian Pendidikan dan Kebudayaan (dasar, menengah, dan atas) baik di tingkat provinsi atau pusat untuk memberikan pelatihanyang bertemakan kualitas layanan yang dapat menciptakan kepuasan peserta didik dan pelatihan yang berorientasi pada peningkatan kualitas kepribadian kepala sekolah agar kepala sekolah dapat menjadi suri tauladan bagi seluruh warga sekolah yang pada gilirannya dapat meningkatkan kualitas pendidikan; dan (3) Hasil penelitian ini dapat menjadi rujukan dalam penelitian tentang kepuasan siswa dan dapat dikembangkandenganmemperdalamdan memperluasvariabel-variabelyanglain sehingga memberikan informasi positif dalam upaya peningkatan kepuasan dan loyalitas siswa.

\section{DAFTAR RUJUKAN}

Anggraeni, G.N., Kusmintardjo., Nurabadi, A. 2016. Implementasi Peran Kepala Taman KanakKanak (TK)dalam Meningkatkan Kinerja Guru. Manajemen Pendidikan. 25 (1): 10-17.

Arikunto, S. 2013. Prosedur Pe-nelitian: suatu pendekatan praktik. Jakarta: Rineka Cipta.

Kusumaningrum, D.E., Triwiyanto, T., dan Gunawan, I.2016. Educational Management of Natural Disaster Response at Lapindo Mudsidoarjo East Java. Journal of Basic and Apllied Scientific Research. 6 (4): 1-8.

Liana, N.A., Benty, D.N., Supriyanto, A. 2016. Analisis Faktor yang Memengaruhi KepuasanOrang Tua Peserta Didik Terhadap Layanan Pendidikan. Manajemen Pendidikan. 25 (1): 39-46.
Sari, Ruri Puspita. Pengaruh Kualitas Pelayanan Sekolah Terhadap Ke-puasan Peserta Didik dan Orang-tua Peserta Didik di SMK Negeri Se-Kota Malang. Tesis. Malang: Jurusan AP FIP UM Malang.

Sugiyono. 2008.Metode Penelitian Pen-didikan: Pendekatan Kuantitatif, Kualitatif dan R\&D. Bandung: Alfabeta.

Tim Penyusun Pedoman Tesis dan Di-sertasi Sekolah Pascasarjana Uni-versitas Muhammadiyah Prof. Dr Haji Abdul Malik Karim Amrul-lah (HAMKA).2008. Pedoman Penulisan Tesis dan Disertasi. Jakarta: UHAMKA Press.

Tjiptono,Fdan Chandra,G. 2007.Service Quality \&Satisfaction, Yogyakarta: AndiPress.

Tjiptono, F. 2008. Prinsip-prinsip Total Quality Service. Yogyakarta: Andi.

Triwiyanto, T. 2015. Pelaksanaan Monitoring, Evaluasi, dan Pelaporan untuk Penilaian Kinerja Manajerial Kepala Sekolah. Cakrawala Pendidikan.34 (1): 67-77.

Triwiyanto, T. 2017. Regrouping of Schools within One Complex and Teacher Redistribution to Attain Equitable Management and Distribution of Teachers. 2nd International Conference on Educational Management and Administration (CoEMA 2017). doi:10.2991/coema-17.2017.3. Diakses tangggal 26 September 2017.

Undang-undang No. 20 Th 2003 ttg Sis-diknas \& UU No. 14 Th 2005 ttg Guru dan Dosen dilengkapi PP No. 19 Th 2005 ttg SNP. 2008. Jakarta: Visimedia.

Yusuf, 4 Mei 2014. Agar Pendidikan Cada Galau, Langkah Perbaikan Sistem Mesti di Alau. Beraupost, hlm. 7. 